\title{
Organizational Diagnosis in the Logistics Sector in Ghana: An Application of the Burke-Litwin Model
}

\section{Coleman $\mathrm{CA}^{1,2 *}$}

${ }^{1}$ Department of Organization \& Human Resource Management, University of Ghana Business School, Ghana 2IMANI Africa Centre For Policy Education, Accra, Ghana

\begin{abstract}
Organizational development (OD) models provide a framework to generate data to diagnose a "case for change" for an organization. The change management literature is replete with many OD models that can be used to diagnose, design, execute and sustain the outcomes resulting from a change management processes. Organizational diagnosis is a very important issue in the field of Organizational Development and Change. It is often the case in studies that organizational change management comes down to answering three questions: why (the causes of change), how (the process of change) and what (the content of change).

This research argues that the Burke-Litwin $(\mathrm{BL})$ model when combined with a change management process (CMP) model provides a useful construct to conduct an organizational diagnosis that provides data to frame a case for change. The integrated BL and CMP framework enables the data generated from the diagnosis to be grounded in both theory and applied research that can be used in real life organizational setting. Using quantitative data, the case study is drawn from a leading organization in the logistics sector in Ghana.
\end{abstract}

Keywords: Research; Organizational; Management; Data; Organizational diagnosis; Organizational change

\section{Introduction}

The advent of technology and competitiveness has triggered a renewed focus on how organizations respond to change in their business environment [1]. Responding to change requires rigorous processes that generate data to diagnosis the case for change for effective decision making. There are many organizational models for diagnosing a case for change. Prominent models reviewed included the Leavit's Model [2] which covers structure, Task, Technology/People, Weisbord's Six Board Model [3], which examines purpose, structure, rewards, helpful mechanism, relationships, leadership, Mckinsey 7S Framework, which defines style, staff, systems, strategy, structure, skills, shared value.

This research examines a case study in the logistics sector in Ghana where the author led a change diagnosis process by combing the $\mathrm{BL}$ Model and CMP model. The Burke-Litwin Mode [4] proposes 12 factors for diagnosis namely external environment, mission and strategy, leadership, organizational culture, structure, systems, management practices, work unit climate, tasks and skills, individual values and needs and individual and overall organizational performance. The CMP model defines four components of the change process. These are diagnosed, design, execute and measure to sustain. Using the findings of the case study, it is argued that the BL model provides conceptual clarity and can be integrated with a CMP model to conduct an organizational diagnosis to inform "a case for change" as well as the required corrective actions to implement the "case for change". It is our expectation that this article will contribute towards further understanding of the theory and practice of organizational diagnosis to inform change management process in the logistics sector in Ghana.

\section{Hypothesis}

Hypothesis 1: The Burke-Litwin (BL) Model provides a comprehensive model for diagnosing a "case for change".

Hypothesis 2: The utility of the BL model is enhanced when it is integrated with a change management process framework that provides an overarching clarity for diagnosis, design, execution and measurement of the entire change management process.

\section{Conceptual Models for Understanding Organization Change}

There are four primary schools of thought on how to understand in broad terms the "how" and the "why" of any change process Van de Ven and Poole [5]. They are life-cycle, teleological, dialectical and evolutionary theories.

\section{Life cycle theory}

Life cycle theory states that an organization "follows" a single sequence of stages which is cumulative (characteristics acquired in earlier stages are retained in the later stage) and conjunctive (the stages are related such that they derive from a common underlying process). Change is inevitable; life cycle theory rests on the metaphor of organic growth which projects an organization as a living organism Burke [6]. An organization may undergo change is it passes through its phases in form and function but nonetheless maintains its identity throughout the phases. Greiner [7] defined five stages in an organization's life cycle: creativity (start-up), direction (more focus needed), delegation (as organization grows larger), coordination (with differentiation of functions integration is then required) and collaboration (working together more effectively as a total entity). Van de Ven and Poole [5] have argued that each of the stages creates dialectical crises of leadership, autonomy, control, red tape etc.

*Corresponding author: Coleman CA, Department of Organization and Human Resource Management, University of Ghana Business School, P.O. Box LG 78, Legon, Accra, Ghana, Tel: +233501581492; E-mail: caselycoleman@yahoo.co.uk

Recieved September 05, 2018; Accepted September 26, 2018; Published October 04, 2018

Citation: Coleman CA (2018) Organizational Diagnosis in the Logistics Sector in Ghana: An Application of the Burke-Litwin Model. J Entrepren Organiz Manag 7: 245. doi: 10.4172/2169-026X.1000245

Copyright: () 2018 Coleman CA. This is an open-access article distributed under the terms of the Creative Commons Attribution License, which permits unrestricted use, distribution, and reproduction in any medium, provided the original author and source are credited. 


\section{Teleological theory}

Teleological theory assumes that an organization is purposeful and adaptive and develops toward a goal or end state Burke [6]. Organization change is a repetitive sequence of goal formulation, implementation, evaluation and modification of goals based on what was learned or intended by the entity. Van de Venn and Poole [5] says Goals may be reached and new ones are set usually as a function of changes in the external environment.

\section{Dialectical theory}

The core thrust of this theory is that organizations exist in a pluralistic world of colliding events, forces or contradictory values that compete with each other for domination and control van de Ven and Poole [5]. Organization change occurs as two different points of view collide and some resolution is reached. Van de Ven and Poole [5] classified Greiner's [7] model of organization development as both life cycle and dialectical.

\section{Evolutionary}

Evolutionary theory assumes that organization change process is analogous to biological evolution, according to a continuous cycle of variation, selection and retention among organizations competing for resources in a designated market place or environment. Organization change then is explained in terms of an ongoing evolving process and there is no permanent equilibrium [6]. Competition for scarce environmental resources between entities inhabiting a particular environment generates this evolutionary change cycle Van de ven and Poole [5].

Whiles Van de Venn d Poole [5] argue that these four types although seem discrete but in reality are not, we will extend that argument and posit that the four types can be integrated into the Burke Litwin model for diagnosing organizational change.

\section{Understanding organizational model}

There are many organizational development (OD) diagnostic models to frame a change management process. A model is a representation of an organization that more often than not is metaphorical in nature [5]. Friedlander and Brown [8] provided a framework for understanding organization change that was based on two primary approaches: human- processual and techno-structural. Porras [9] has provided a model of an organization that consists of four components: organizing arrangements such as goals, social factors such as culture, technology such as tools, and physical settings such as space. These four components together with organizational member's behavior form the throughput dimension of his model [6].

An organizational model can help to categorize data, activities and behavior in an organization. It also helps to enhance our understanding of an organization in order to diagnose problems requiring corrective action [6]. An organizational model can help to guide action for change. However Morgan [10] has argued that using an organizational model as a metaphor is inherently paradoxical since it can create a powerful insight that also become distortions as the way of seeing created in the same vein can become a way of 'not seeing".

Burke [6] argues that many current models are based on the earlier thinking of Harold Leavitt [2]. Leavitt's model although descriptive, defined four major components namely task (the organization's purpose e.g., to provide a service), people (those who carry out the task), technology (tools computers, we will extend and add social media etc.) structure (work flow decision making authority, communication etc.). In the same vein Leavitt's model pointed out that change in any one of the components will result in change amongst the other three. Prominent models include the Leavitt's Model [2] which covers structure, task, Technology/People, Burke [6] argues that Leavitt's [2] version although grounded in systems thinking was not based on open systems theory since the model represents only throughput with no accounting for input or output. Weisbord's Six Board Model [3], defines an organization as made up of purpose, structure, rewards, helpful mechanism, relationships, leadership, Mckinsey 7S Framework, defines an organization as composing of style, staff, systems, strategy, structure, skills, shared value.

\section{Burke-Litwin model}

Our case study adopted the Burke Litwin model since we felt it was relatively comprehensive to guide data driven organizational diagnosis of the case for change. The Burke-Litwin Mode [4] defines twelve factors that helps to diagnose the case for change as well as the overall change processes namely external environment, mission and strategy, leadership, organizational culture, structure, systems, management practices, work unit climate, tasks and skills, individual values and needs and individual and overall organizational performance (Figure 1).

\section{Key Definitions of the BL Model}

External environment: The key forces or variables outside the organization that influence organizational performance e.g., customer behavior and satisfaction, market place conditions, political circumstances, regulations, changing technology etc.

Mission and strategy: Mission concerns what the organization is all about, its purpose and primary goals. Strategy focus on how the mission is to be executed as defined by senior leadership.

Leadership: This is concerned with behavior of senior executives and how they provide direction, influence, visioning. We extend this to include definition of decision space and decision mandate.

Organizational culture: Values i.e., espoused and in-use, explicit

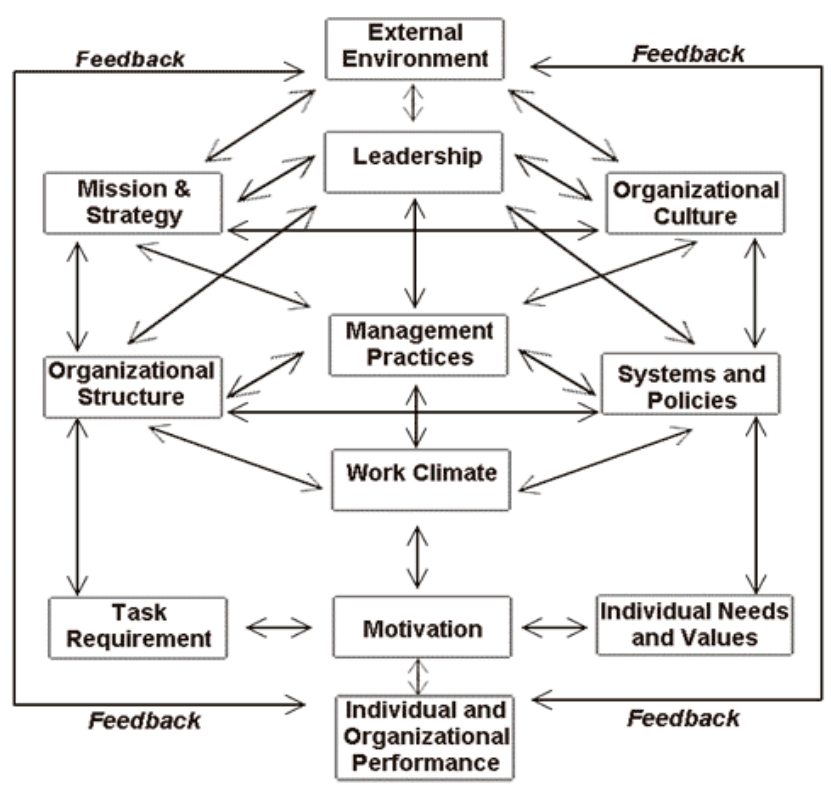

Figure 1: Burke-Litwin model. 
as well as the implied rules, regulations, customs, principles, practices, symbols, artifacts, rituals that influence the interaction of staff and the organization.

Structure: Responsibility authority, communication, decision making and control structure that exists between the people of the organization.

Systems: Systems includes all types of policies, procedures and business processes with regards to both the people and the operations of the organization.

Management practices: Ways of work that delivers the organization's strategy and ensures management of resources.

Work unit climate: Refers to how the employees think, feel, and the kind of relationships the employees share with their team members and members of other teams.

Tasks and skills: Refers to what a specific job position demands and the kind of skills and knowledge that an employee must have in order to fulfill the task responsibilities of that job position. It helps to see how well jobs and employees have been matched.

Individual values and needs: This refers to employee's opinion about their work so as to identify the quality factors that will result in job enrichment and better job satisfaction.

Motivation level: Refers to the motivation level of the employees, and willingness to put in extra effort to achieve organizational goals.

Individual and overall performance: This dimension takes into account the level of performance, on individual and organizational levels, in key areas like productivity, quality, efficiency, budget and customer satisfaction etc.

\section{Integrating the Four Schools of Thought and the BL Model}

The 12 key dimensions of the change model interact with and affect each other. Understanding the linkage between these dimensions within the framework of the life cycle of the organization in response to competing pressures from the wider environment is the key to effective diagnosis, execution, measurement and sustainability of the change process. The most dominant factor that triggers organizational change is the external environment. It is the external environment that makes an organization to change its mission, culture, leadership and its internal business processes and strategies. This aligns with the teleological, dialectical and evolutionary school of though.

We see linkages between the four schools of thought namely lifecycle, teleological, dialectical and evolutionary theories and the BL model.

\section{Change Management Process Model}

A change management process has to be grounded on a clear process framework. Namely: diagnose, design, execute and learn \&sustain, reinforced by people, conversations, interventions and tools. This model is an adaptation of the classical project management cycle which defines conceptualizing, planning, executing and termination Pinto and Slevin [11].

The diagnose phase is usually the first stage which is an organizational review of the twelve key organizational change factors. The outcomes of the diagnose process informs the design and execute phases to frame the required corrective actions in order to guide learning, measurement and sustainability of the change process. The entire cycle requires extensive engagement with key organizational stakeholders i.e., leaders, managers and employees (Figures 2 and 3).

The integrated BL\& CMP model argues that:

1. Any change management diagnostic process must be built on a solid foundation made up of four key elements namely diagnose, design, execute and sustain.

2. This foundation when combined with the BL model provides the basis for generating comprehensive data to frame the diagnosis of the "case for change".

\section{Case Study}

\section{Introduction}

Established in 2001, the organization is one of the leading freight forwarding companies in Tema the main port city of Ghana with a global logistics services delivery model with a focus on client's satisfaction. The company has established itself as one of the most reliable players in the freight forwarding sector and is poised to grow with the potential to become the leading freight forwarding and logistics company in Ghana and within the sub region. The company currently employs over 80 full

\section{Change Management Process Framework}

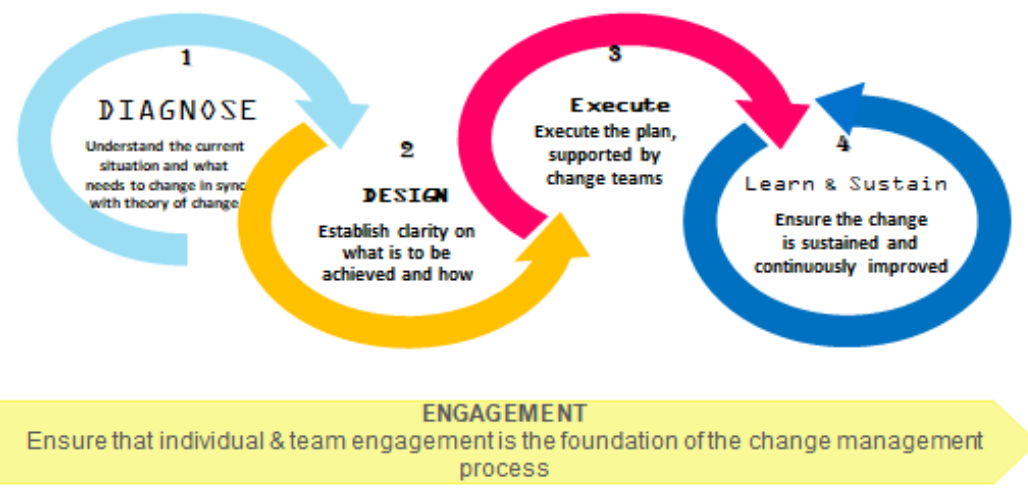

Figure 2: Change management process model. 


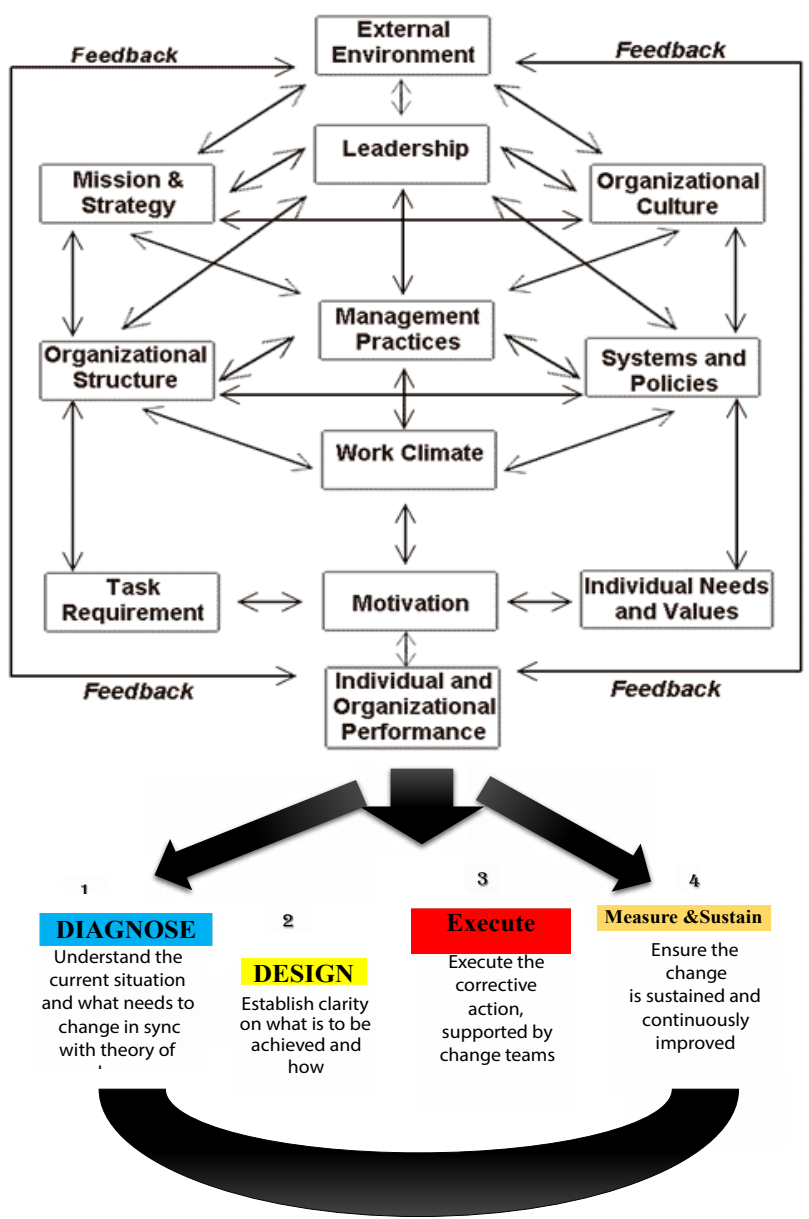

Figure 3: Integrating BL and CMP models.

time staff with an average turnover of $\$ 5 \mathrm{~m}$ and is currently embarking on expanding its business by building a new terminal, acquiring new clients and also sustaining current competitiveness in a rapidly changing business landscape $[12,13]$.

The organization's portfolio of clients has grown to include some of the most influential and dynamic global brands in Ghana. In the same vein, the clearing and freight forwarding industry landscape has changed significantly over the last decade, resulting in keen competition within the industry. Presently, there is over three hundred and fifty freight forwarding companies in Tema alone. The phenomenal increase in freight forwarding organizations has triggered stiff competition in the industry and only innovative clearing and freight houses can survive the competition. Staying competitive requires getting a clear business strategy, reinforced with the right organizational design and resourced with the right talent with information communication and technology capabilities to deliver low cost high impact business model. A new approach to business is required to drive expansion in line with the vision to become a top logistics company in the sub Saharan region in the next ten years from 2018 to 2028. It is on this basis that a change management process was launched. Following initial discussions with the leadership team, the purpose of the organizational review process was to conduct a diagnosis of the effectiveness and efficiency of its current organizational structure and management systems, identify capabilities and gaps and make recommendations to address them [14].

\section{Methodology}

The methodology used to generate data to inform the diagnosis included interviews with staff, testing of evidence of existence or otherwise of internal controls, observations and review of documents. A total of 53/86 staff was interviewed i.e., $61 \%$. This represents a strong statistical sample to make generalizations of staff perceptions and concerns. In terms of gender diversity of staff. $12 / 86$ i.e., $14 \%$ are females and 12/53 i.e., $22 \%$ interviewed staff are females [15].

\section{Conceptual framework for organizational diagnosis}

The Burke-Litwin model was used as the organizational diagnostic tool to conduct the review. The model defines twelve key variables that are very critical to diagnose the need for change to ensure organizational effectiveness. These are external environment, mission and strategy, leadership, organizational culture, systems, management practices, roles and responsibilities, structure, work unit climate, individual needs and values, motivation and performance etc. Edgar Schein's concept of organizational culture was also a source of reference in diagnosing the 'way things are done here" in the company [16].

\section{External environment}

This includes such factors as markets, legislation, competition and the economy. All of these will have consequences for organizations, any 
change management process diagnosis, needs to scan the environment [17].

Diagnosis: (a) There was no evidence that the organization has done market competitiveness survey, reviewed relevant regulatory frameworks i.e., legislation, policies, and standards etc. and the risks and implications for its operations; (b) There was no evidence that staff are aware of the evolving regulatory trends in the sector.

Corrective actions recommended: It included (a) need to map out key external environmental trends (b) conduct a comprehensive external environment scan/review that will highlight risks, constraints, opportunities and opportunities to inform a new strategy and organizational design [18].

\section{Mission and strategy}

An organization's mission articulates its reason for existing. It is the foundation upon which all operations, products and services should be built. The strategy then sets out, in broad terms, how the organization will go about achieving its mission. Very often, the strategy will be developed in light of external environmental trends, and will have a significant impact on the work staff do and be able to communicate the implications to your staff [19].

Diagnosis: Apart from one management staff, none of the staff could articulate the organization's mission even though it is on the company website. Many staffs were not aware of any existing documented company business strategy and aspirations.

Corrective actions recommended: It included (a) need to define a set of core values and behaviors (b) need to train staff on the core values and behaviors (c) need to integrate the core values and behaviors into all HR processes and outcomes including selection, induction, performance management, compensation, learning and development.

\section{Leadership}

This considers the attitudes and behavior of senior colleagues and how these behaviors are perceived by the organization as a whole. The way in which change is implemented and accepted through the organization will be largely influenced by the top team [20].

Diagnosis: There was a degree of skepticism on the part of majority of staff interviewed i.e., $85 \%$ on the extent to which they believe that senior colleagues are committed to change.

Corrective actions recommended: It included (a) need to provide training to management team on how to lead and manage change (b) need to define new values driven leadership standards and assess current team of leaders against those standards (c) need to provide continuous leadership development programs for line managers and supervisors.

\section{Organization culture}

Organization culture can be described as "the way we do things around here". It considers the beliefs, rituals, traditions, behaviors, values and conventions that prevail in an organization.

Diagnosis: There is a perception that there is too much reliance on CEO to push things creating a dependency syndrome. $60 \%$ of staff had a perception that people are hired based on family relationships or friendship basis and not always based on merit and this leads to favoritism. $90 \%$ of staff interviewed had a perception that the culture of not having management and staff meetings discouraged interactions between Management and staff on the wellbeing and performance of the organization.
Corrective actions recommended: It included (a) need to establish and document the core values and behaviors expected of staff (b) need to ensure the core values are displayed at vantage places in all offices (c) need to strengthen selection and recruitment methodologies to ensure transparency (d) need to establish regular monthly management team meetings and quarterly management and staff meetings.

\section{Systems}

Systems include all types of policies and procedures with regards to both the people and the operations of the organization.

Diagnosis: There are no written policies, procedures and guidelines on the nine core areas of risk management, finance, procurement and administration, security, legal, ICT, HR, warehouse and sales/ marketing.

Corrective actions recommended: It included (a) need to develop written policies, procedures and guidelines on all the nine core areas (b) need to train management and staff on the policies, procedures \& guidelines (c) need to have an independent audit of the implementation of the new policies, procedures and guidelines at least once a year after they have been put into place.

\section{Management practices}

This examines how well managers conform to the organization's strategy when dealing with employees and company resources.

Diagnosis: There is a prevailing practice where many staff i.e., $68 \%$ of staff files sampled is hired without written employment contract, there is no systematic process for assessing staff performance and there is no documented process for supporting staff learning and development. In addition there is no evidence that staff is aware of the future strategic intent and aspirations of the company to ensure staff performance are aligned to the company's business strategy. There is also no evidence of a standard induction tool-kit that provides a thorough induction of the company' vision, mission, values, business strategy and key company policies etc. to newly hired staff.

Corrective actions recommended: It included (a) develop a business strategy to define the strategic intent and aspirations for the company for the next 5 years (b) develop a new organizational design that aligns to the strategy and helps to deliver and measure the strategy (c) conduct extensive staff engagement on the new strategy and design to ensure staff are aware, understand, commit to the strategy and their individual contributions to the delivery of the strategy can be measured. (d) develop a new staff induction framework and toolkit.

\section{Roles and responsibilities and skills}

This involves understanding what a specific job position demands and the kind of competencies an employee must have in order and knowledge that an employee must have in order to fulfill the task responsibilities of that job position. It's important to see how well jobs and employees have been matched.

Diagnosis: An overwhelming majority of staff interviewed 70\% of overall staff as well $68 \%$ of 25 personal files sampled had no written job descriptions. There was an example of a proliferation of titles i.e., chief driver, assistant chief driver, and senior driver but there was no clear cut differentiation of the roles and responsibilities of these positions.

Corrective actions recommended: It included (a) need to identify core mission critical roles (b) develop job descriptions for the roles (c) conduct a job evaluation exercise using HAY job evaluation tool 
(know-how, accountability \& problem solving) to establish a Job Grading/classification system (d) conduct a salaries and benefits bench marking survey (e) develop a pay structure (f) train HR team on how to administer, monitor, evaluate implementation to ensure continuous improvement and sustainability.

\section{Structure}

Assessment of the extent to which a function based structure pervades in the organization with a focus on responsibility, authority, communication, decision making and control structure that exists between the people of the organization.

Diagnosis: There is no evidence of an approved organizational structure which is available and understood by staff.

Corrective actions recommended: It included (a) develop a revised organizational structure based on the finding of the organizational review (b) get it approved by management (c) create staff awareness by socializing the structure and make it available to all staff.

\section{Work unit climate}

This considers employees' perception of their immediate colleagues and working environment. Employees' immediate working environment is often what shapes their view of the organization as a whole, and influences the extent to which they feel satisfied in their jobs.

Diagnosis: here is a perception by $55 \%$ of staff interviewed, that management does not trust them especially in the area of advances liquidation, and this has created low motivation. There is a perception of favoritism in the allocation of company vehicles to staff and there is a concern that new staff are paid higher than old staff. Corrective actions recommended: It included (a) establish systematic documented process map and guidelines for advances management and expenditure using ICT tools (b) train staff on the process (c) ensure compliance through planned and unplanned checks/reviews and apply corrective action where there is noncompliance in line with due administrative justice processes as defined in the new company HR manual to be developed. (f) hold quarterly team building sessions to sustain high trust dynamics amongst staff.

\section{Individual needs and values}

This refers to employee's opinion about their work so as to identify the quality factors that will result in job enrichment and better job satisfaction.

Diagnosis: There are no documented policy and procedures to support staff professional and career development. Corrective actions recommended: It included (a) develop policy \& procedures on professional and career development (b) adapt proven talent management tools i.e. job rotation, job enrichment, cross functional projects etc. to reinforce alignment of individual staff potential and skills to company's business strategy and objectives.

\section{Employee motivation}

Consider the significance of individual and organizational goals. Motivation is the key to effective change. The real challenge is to maintain motivation throughout a change project, particularly when change is often not well-received by those affected.

Diagnosis: Over $90 \%$ of staff interviewed complained about the low levels of salaries and very few benefits. There is also a high level of frustration by majority of drivers on three key aspects of motivation i.e., lack of respectful communication from their supervisors, lack of supervisors picking their calls or inadequate level of responsiveness when they encounter problems on their travels especially during weekends and inadequate out of station allowances. Specifically amongst drivers, there is overwhelming sentiments that the CEO has a good heart and cares for the staff; however they cannot say the same for their line manager.

Corrective actions recommended: It included (a) develop a new rewards framework (b) train managers on the framework (c) provide technical support to HR team to manage the framework.

\section{Organizational performance}

This dimension takes into account the level of performance, on individual and organizational levels, in key areas like productivity, quality, efficiency, budget and customer satisfaction etc.

Diagnosis: There is lack of alignment between the company's strategic intent and aspirations and current management of staff performance.

Corrective actions recommended: It included (a) implement findings of the organizational review to help develop a new organizational design (b) use new organizational design to restructure the company's operations (c) establish a performance management system (d) document the learning from the change management process. In the light of the above diagnosis which was framed using the BL model, a change management action plan has been developed and framed around the twelve factors, providing a clear theory of change on what success will look like once the corrective actions have been put in place $[21,22]$

\section{Corrective Actions Plans}

Even though it is not a part of the organizational diagnosis, the identification of corrective actions from the cause-and effect analysis is a sine-qua-non for defining the theory of change to guide the overall change management process. The data generated from the diagnosis, helps to draft a measurable corrective action plan for each of the twelve factors diagnosed. Very critical elements of the corrective action plan include identification of key accountability, responsibility, consulting and informing roles reinforced with key performance indicators for measuring the execution of corrective action plans $[23,24]$.

\section{Conclusions}

Organizational development theory research and practice confirms that any initiative to diagnose the strengths, weaknesses, opportunities and risks to change to realign an organization to a desired "theory of change" must be anchored on a thorough organizational diagnosis. Organizational diagnosis using an appropriate OD model provides a basis for an organization to diagnose cause-and-effect within its internal and external context as it delivers its products and services. An organizational diagnosis enabled by an appropriate OD models helps to examine the overall contextual realities to analyze historical precedents and current realities in order to map out a current versus future desired theory of change. The Burke Litwin model was combined with a change management process model and adapted to guide the organizational diagnosis process and outcomes and this helped to illustrate key strengths, gaps and opportunities and determine causeand-effect relationships to trigger the case for change.

An organizational diagnosis process review also requires a solid 
literature review of various organization development (OD) options to conceptually frame the diagnosis. A review of four OD diagnostic models led to the selection of the Burke Litwin model which provided the overall conceptual framework for the review. The diagnostic model selected helped to determine the extent of change readiness required and the corrective actions to deliver the identified gaps. The BurkeLitwin model is a very practical diagnostic tool for conducting a change diagnosis review. The model provides flexibility to examine the twelve key variables that are very critical to diagnose the need for change to ensure organizational effectiveness. These are external environment, mission and strategy, leadership, organizational culture, systems, management practices, roles and responsibilities, structure, work unit climate, individual needs and values, motivation and performance.

Organizational diagnosis plays a vital role in organizational change initiatives however little attention has been invested in the rigor of the diagnostic process itself. The absence of a thorough diagnosis process can potentially restrict the availability of data driven insights that can result in the failure of transformational initiatives. This article has reviewed evidence from the logistics sector and avers that a thorough organizational diagnosis framed around an integration of the Change Management Process Model (CMP) and the Burke Litwin (BL) model can facilitate the identification of cause-effect relationships that underpin evidence-based organizational diagnosis.

Based upon that review, the integrated $\mathrm{CMB}$ and $\mathrm{BL}$ evidencebased approach is proposed as a conceptual model for organizational diagnosis as it enables data driven social scientific rigor to the organizational diagnostic process. The model also helps to strengthen the appropriateness of interventions chosen for a given situation and contributes to willingness-to-change across the organization from senior management to employees. In addition, the data driven organizational diagnosis provides the basis for corrective action to address the gaps identified.

As a result of this case study we conclude that the application of the BL model when combined with a change management process (CMP) model provides clarity for organizational diagnosis. Secondly it ensures a strong nexus between the breadth and depth of the organizational diagnosis, and the data methodology tools to be applied to diagnose the key organizational factors requiring change. Thirdly it provides the basis for all organizational stakeholders to conceptualize the various linkages in the model to critique and assure quality in data analysis and drive engagement around design choices. This is imperative for resolving disagreements amongst key actors involved in the diagnostic review i.e., change consultant, leadership, change champions and staff in general.

The combination of the BL model and CMP model helps to provide an overarching framework to follow up on the diagnosis in order to design, execute, measure and sustain the corrective actions. Although this study focuses on only once case study in the logistics sector in Ghana, its findings can be subjected to further studies to contribute towards the theory, research and practice of organizational diagnosis in change management processes.

\section{Limitations}

This article is intentionally restricted to the organizational diagnosis component which is the primary step in the organizational change management process. While other phases of the organizational change process remain beyond the scope of this paper, we have nonetheless defined diagnosis within the overall change management process which includes design, execution, measurement and learning.
The three components of organizational change management processes are very relevant both from the theoretical and application perspectives. However, these key components of the change management process were outside the scope of this research. The examination of the three remaining components of the organizational change management will be the focus of our next research when we review the outcomes of the design, execution, measurement and learning of the corrective actions.

We think a significant mitigation of the limitation indicated above is the availability of empirical research from the case study from the logistics sector in Ghana that enables the validation of the conclusions presented in this work. The case study used in this paper is intended to address that gap.

\section{References}

1. Pettigrew A (1989) Pettigrew A editor. The Management of Strategic Change. London: Basil Blackwell, p: 370.

2. Leavitt HJ (1965) Applied Organizational Change in Industry: Structural, Technological and Humanistic Approaches. In: March JG editor. Handbook of organization. Rand McNally and Company, Chicago, Illinois.

3. Weisbord MR (1976) Organizational Diagnosis: Six Places to Look For Trouble With or Without a Theory. Group and Organization Studies

4. Burke WW, Litwin GH (1992) A Causal Model of Organizational Performance and Change. Journal of Management 18: 523-545

5. Van de Ven AH, Poole MS (1995) Explaining Development and Change in Organizations. Academy of Management Review 20: 510-540.

6. Burke WW (2011) Organization Change, Theory and Practice. Sage Publications.

7. Greiner L (1972) Evolution and Revolution As Organizations Grow. Harvard Business Review 50: 37-46.

8. Friedlander E, Brown L (1974) Organization Development. Annual Review of Psychology 25: 313-341.

9. Porras Jl (1987) Stream Analysis: A Powerful Way to Diagnose and Manage Organizational Change. Pearson.

10. Morgan G (1997) Images of Organization. CA: Sage

11. Pinto JK, Slevin DP (1988) Critical Success Factors in Effective Project Implementation.

12. McFillen JM, O'Neil DA, Balzer WK, Varney GH (2013) Organizational Diagnosis: An Evidence-based Approach. Journal of Change Management.

13. Davis SA (1967) An Organic Problem Solving Method of Organizational Change. Journal of Applied Behavioral Science 3: 3-21.

14. Jones G (2013) Organizational Theory, Design and Change, New York: Addison Wesley.

15. Lawrence PR, Lorsch JW (1969) Developing Organizations: Diagnosis and Action. Reading, MA: Addison-Wesley Publishing Company.

16. Lawrence PR, Lorsch JW (1967) Organizations and Environment Managing Differentiation and Integration. Harvard University Press.

17. Legge K (1984) Evaluating Planned Organizational Changes. Orlando, FL: Academic.

18. Morgan G (1983) Beyond Methods: Strategies for Social Research. Beverly Hills, CA: Sage.

19. Tushman M (1995) Types of Organizational Change: From Incremental Improvement to Discontinuous Transformation. Harvard Business School.

20. Porras JI, Robertson PJ (1992) Organization Development: Theory, Practice and Research. Handbook of Industrial and Organizational Psychology pp: 719-822.

21. Porras JI, Silvers RC (1991) Organization Development and Transformation Annual Review of Psychology 42: 51-78.

22. Schein EH (1965) Organizational Psychology. Oxford, England: Prentice Hall. 
Citation: Coleman CA (2018) Organizational Diagnosis in the Logistics Sector in Ghana: An Application of the Burke-Litwin Model. J Entrepren Organiz Manag 7: 245. doi: 10.4172/2169-026X.1000245

Page 8 of 8

23. Schein EH (1983) The Role of the Founder in Creating Organizational Cultures. Organizational Dynamics 12: 13-28.
24. Weick KE (2001) Making Sense of the Organization: Volume 2 The Impermanent Organization. Hoboken, NJ: John Wiley \& Sons, pp: 312. 